\title{
Erratum: Developing services for long COVID: lessons from a study of wounded healers
}

\author{
Authors: Emma Ladds, ${ }^{\mathrm{A}}$ Alex Rushforth, ${ }^{\mathrm{B}}$ Sietse Wieringa, ${ }^{\mathrm{C}}$ Sharon Taylor, ${ }^{\mathrm{D}}$ Clare Rayner, ${ }^{\mathrm{E}}$ Laiba Husain ${ }^{\mathrm{F}}$ and \\ Trisha Greenhalgh ${ }^{G}$
}

Clinical Medicine 2021;21:59-65.

This article was originally published as a paper in the special section on functional disorders in the January 2021 issue of Clinical Medicine. It should have been published as a standalone original research paper, and this has been corrected in the online edition of the journal. The editor-in-chief and editorial office apologise for this error.

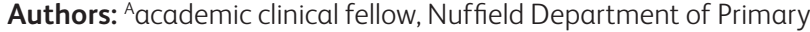
Care Health Sciences, Oxford, UK; ${ }^{B}$ postdoctoral researcher, Nuffield Department of Primary Care Health Sciences, Oxford, UK; Cpostdoctoral clinical researcher, Nuffield Department of Primary Care Health Sciences, Oxford, UK; ' ${ }^{D}$ child psychiatrist and honorary senior lecturer, Central and North West London NHS Foundation Trust, London, UK and Imperial College London, London, UK; Egeneral practitioner, independent occupational physician, Manchester, UK; Fresearch assistant, Nuffield Department of Primary Care Health Sciences, Oxford, UK; ${ }^{G}$ Clinical professor, Nuffield Department of Primary Care Health Sciences, Oxford, UK
} 